\title{
ANALISIS SUSUNAN MENU KANTIN KARYAWAN DI KYRIAD HOTEL BUMIMINANG PADANG
}

\author{
Yudha Baskoro Putra ${ }^{1}$, Lise Asnur ${ }^{2}$ \\ 1,2 Program Studi D4 Manajemen Perhotelan, Jurusan Pariwisata \\ FPP, Universitas.Negeri Padang, Indonesia \\ e-mail: yudhabaskoroputra@gmail.com ${ }^{1}$, lise.asnur@fpp.unp.ac.id ${ }^{2}$
}

\begin{abstract}
Abstrak
Penelitian ini berjudul.Analisis Susunan Menu Kantin Karyawan Di Kyriad Hotel Bumiminang Padang. Tujuan dari penelitian ini.adalah untuk menganalisis susunan menu di kantin karyawan Hotel Kyriad Hotel Bumiminang Padang. Adapun keluhan yang dapat ditemukan oleh peneliti adalah salah satunya yaitu cita rasa, tekstur,.warna yang kurang bervariasi.terhadap makanan yang dihidangkan di kantin karyawan Hotel Kyriad Bumi Minang Padang. Penelitian ini merupakan penelitian..deskriptif kuantitatif dengan metode survey Jumlah sampel.dalam penelitian ini adalah 66 responden. Cara pengambilan sampel.dengan menggunakan teknik non probability sampling. Jenis non probability sampling yang digunakan adalah sampling..jenuh. Data dikumpulkan menggunakan kuesioner atau angket dengan menggunakan skala.likert. Teknik analisis data dilakukan dengan menggunakan program computer..SPSS versi 20.00. Hasil penelitian ini menunjukkan.bahwa: Susunan menu..kantin karyawan Kyriad Hotel Bumiminang Padang berada padaakategori Baik dengan nilai persentase $27 \%$ yang artinya susunan menu di kantin karyawan Kyriad Hotel Bumiminang Padang sudah baik sesuai dengan keinginan danaaharapan dari karyawan Kyriad Hotel Bumiminang Padang.
\end{abstract}

Kata kunci: Analisis,.Susunan.Menu, Kyriad Hotel Bumiminang Padang

\begin{abstract}
The research entitled Analysis of Employee Canteen Menu Arrangement at Kyriad Hotel Bumiminang Padang. The purpose of this study was to analyze the menu arrangement in the employee canteen of the Kyriad Hotel Bumiminang Padang Hotel. One of the complaints that can be found by researchers were the taste, texture, and color are less varied to the food served in the employee canteen of the Hotel Kyriad Bumi Minang Padang. This research was a descriptive quantitative research with a survey method. The number of samples in this study were 66 respondents. The sampling method uses non probability sampling techniques. Non probability sampling used was saturated sampling. Data were collected using a questionnaire using a Likert scale. The data analysis technique was performed using the SPSS version 20.00 computer program. The results of this study indicate that: The menu arrangement of the Kyriad Hotel Bumiminang Padang employee canteen is in the Good category with a proportion value of 27\%, which means that the menu arrangement in the Kyriad Hotel Bumiminang Padang employee canteen is good according to the wishes and expectations of the employees of the Kyriad Hotel Bumiminang Padang.
\end{abstract}

Keywords: Analysis, Menu Arrangement, Kyriad Hotel Bumiminang Padang 


\section{Pendahuluan}

Kota Padang adalah Ibukota dari Provinsi Sumatera Barat, Kota Padang juga merupakan kota terbesar di Sumatera Barat dan juga merupakan pintu gerbang barat Indonesia dari Samudera Hindia. Kota Padang yang terkenal akan legenda Malin Kundang dan Siti Nurbaya ini sedang gencar akan pertumbuhan pariwisatanya. Bukan hanya terkenal dengan objek wisatanya yang banyak, Kota Padang juga terkenal dengan makanannya yang populer di kalangan rakyat Indonesia seperti Rendang, Sate Padang, Dendeng Balado dan masakan daerah lainnya. Oleh karena itu Kota Padang menjadi salah satu tempat yang menarik untuk dikunjungi oleh wisatawan.

Sektor pariwisata di Kota Padang semakin memajukan eksistensinya baik ditingkat Nasional maupun Internasional, hal ini terbukti dengan banyaknya dibangun hotel-hotel atau restaurant serta objek wisata sehingga banyak pengunjung atau wisatawan lokal maupun mancanegara yang ingin menggunakan fasilitas tersebut, jadi tidak heran lagi bila banyak kota-kota lain yang berusaha meningkatkan pariwisatanya.

Akomodasi adalah salah satu kebutuhan bagi para wisatawan ketika melakukan perjalanan pariwisata. Menurut Rizal Kurniansah dan Muhammad Sultan Ali $(2018 ; 41)$ "Akomodasi pariwisata adalah suatu tempat yang diperuntukkan untuk para wisatawan ketika berkunjung di daerah wisata, seperti hotel, villa, wisma, bungalow, maupun homestay". Pada saat sekarang ini akomodasi yang paling sering digunakan adalah hotel, Hotel adalah Usaha Hotel adalah usaha penyediaan akomodasi berupa kamar-kamar di dalam suatu bangunan, yang dapat dilengkapi dengan jasa pelayanan makan dan minum, kegiatan hiburan dan/atau fasilitas lainnya secara harian dengan tujuan memperoleh keuntungan (Peraturan Menteri Pariwisata dan Ekonomi Kreatif Republik Indonesia).

Karyawan Hotel merupakan tenaga penggerak yang paling penting bagi hotel sehingga diperlukan kesehatan baik itu jasmani maupun rohani, karena sebuah hotel tidak akan berjalan dengan baik jika karyawan memiliki kesehatan yang tidak baik sehingga hotel harus bertanggung jawab atas kesehatan para karyawannya. Oleh sebab itu langkah awal bagi hotel untuk menjaga kesehatan karyawannya adalah dengan menyediakan makanan yang sehat dan bergizi serta menggugah selera sehingga karyawan tidak akan bosan akan makanan yang disediakan oleh hotel dan juga akan menjaga kesehatan bagi karyawan hotel yang bekerja.

Susunan menu makanan adalah susunan atau daftar hidangan yang akan disiapkan sebagai makanan. Menurut Kokom Komariah Marwanti $(2010 ; 6)$ Menu adalah "Sususan hidangan yang disiapkan untuk disajikan sebagai makanan, daftar makanan yang bisa dipesan, misalnya pada suatu pesta atau acara tertentu.". Susunan menu termasuk suatu tahap perencanaan dalam pengolahan makanan, agar dalam pelaksanaannya dapat berhasil dengan baik, maka dalam penyusunan menu harus mengetahui dasar-dasar dalam penyusunan menu seperti mengetahui tujuan penyusunan menu untuk makanan sehari-hari atau menu untuk jamuan khusus, kebutuhan gizi, waktu makan dan mengetahui jumlah yang akan makan.

Berdasarkan hasil wawancara dengan salah satu karyawan Hotel Kyriad Bumi Minang pada tanggal 6 maret 2020 menu makanan karyawan Hotel Kyriad Bumi Minang yang disajikan di kantin karyawan terkadang tidak sesuai dengan daftar menu yang telah ditetapkan, hal tersebut dikarenakan bahan makanan yang akan disiapkan tidak tersedia sehingga pihak hotel harus mengganti menu yang akan dihidangkan, seharusnya pihak hotel harus menyiapkan bahan makanan yang akan di olah dan mengetahui musim dari bahan makanan yang ada pada saat itu sehingga bahan makanan yang dijual di pasar akan tersedia sehingga makanan yang dihidangkan di kantin karyawan sesuai dengan menu yang telah di tetapkan. Masalah kedua yang menjadi keluhan dari karyawan adalah cita rasa dari makanan yang membosankan, hal tersebut dikarenakan menu yang kurang bervariasi sehingga karyawan merasa bosan akan makanan yang dihidangkan di kantin karyawan, seharusnya pihak hotel memvariasikan menu yang akan disajikan sehingga karyawan merasa puas terhadap makanan yang ada di kantin karyawan tersebut. Oleh sebab itu, penulis menawarkan untuk melakukan penelitian ini dengan judul "Analisis Susunan Menu Karyawan Di Hotel Kyriad Bumi Minang Padang". 


\section{Metode}

Jenis penelitian ini adalah deskriptif dengan data kuantitatif dan metode survey yang bertujuan untuk menganalisa susunan menu di kantin karyawan Kyriad Hotel Bumiminang Padang. Pengumpulan data dilakukan melalui kuesioner atau angket dengan skala likert yang terdiri dari 25 pernyataan, yang mana telah teruji validitas dan reliabilitasnya. Populasi dalam penelitian ini adalah seluruh karyawan yang makan di kantin karyawan Kyriad Hotel Bumiminang Padang sebanyak 66 orang. Menurut Sugiyono (2018;130) "Populasi adalah wilayah generalisasi yang terdiri atas: obyek/subyek yang mempunyai kuantitas dan karakteristik tertentu yang diterapkan oleh peneliti untuk dipelajari dan kemudian ditarik kesimpulannya". Pengambilan sampel dilakukan menggunakan teknik non probability sampling dengan metode sampling jenuh, dengan jumlah responden 66 orang. Teknik analisis data dilakukan dengan menggunakan program komputer SPSS versi 20.00. Data dalam penelitian ini didapatkan dengan melakukan penyebaran angket, kemudian diolah. Dengan cara menyajikan data kedalam tabel distribusi frekuensi, menghitung nilai rata-rata kemudian diklasifikasikan kedalam beberapa kategori yaitu Sangat Baik, Baik, Kurang Baik, Tidak Baik, dan Sangat Tidak Baik.

\section{Hasil dan Pembahasan}

\section{A. Analisis Deskriptif Variabel Susunan Menu}

Tabel 1. Klasifikasi Skor Variabel Susunan Menu

\begin{tabular}{lccc}
\hline \multicolumn{1}{c}{ Kategori } & Rentang Skor & Frekuensi & $\%$ \\
\hline Sangat Baik & $\geq 106,45$ & 14 & 21 \\
Baik & $\mathbf{1 0 0 , 2 5 - 1 0 6 , 4 5}$ & $\mathbf{2 7}$ & $\mathbf{4 1}$ \\
Kurang Baik & $93,75-100,25$ & 9 & 14 \\
Tidak Baik & $87,55-93,75$ & 9 & 14 \\
Sangat Tidak Baik & $\leq 87,55$ & 7 & 10 \\
\hline \multicolumn{2}{r}{} & & \multicolumn{3}{c}{ Sumber: Data Olahan (2020) }
\end{tabular}

Berdasarkan Tabel 1 diatas terlihat bahwa responden menyatakan mengenai susunan menu kantin karyawan Kyriad Hotel Bumiminang Padang dengan kategori Sangat Baik 21\%, kategori Baik 27\%, kategori Kurang Baik 9\%, kategori Tidak Baik 9\% dan kategori Sangat Tidak Baik 7\%. Dengan demikian dapat disimpulkan susunan menu di kantin karyawan Kyriad Hotel Bumiminang Padang dominan berada pada kategori Baik. sebagai berikut:

Selanjutnya variabel manajemen diklasifikasikan dengan masing-masing indikator,

\section{B. Standar Porsi}

Tabel 2. Klasifikasi Skor Variabel Susunan Menu dari Standar Porsi

\begin{tabular}{|c|c|c|c|}
\hline Kategori & Rentang Skor & Frekuensi & $\%$ \\
\hline Sangat Baik & $\geq 33,45$ & 23 & 35 \\
\hline Baik & $31,15-33,45$ & 18 & 27 \\
\hline Kurang Baik & $28,85-31,15$ & 12 & 18 \\
\hline Tidak Baik & $26,55-28,85$ & 4 & 6 \\
\hline Sangat Tidak Baik & $\leq 26,55$ & 9 & 14 \\
\hline \multicolumn{2}{|c|}{ Total } & 66 & 100 \\
\hline
\end{tabular}

Sumber: Olahan Data Primer (2020)

Berdasarkan Tabel 2 diatas terlihat bahwa responden menyatakan mengenai susunan menu kantin karyawan Kyriad Hotel Bumiminang Padang ditinjau dari Standar Porsi dengan kategori Sangat Baik 35\%, kategori Baik 27\%, kategori Kurang Baik 18\%, kategori Tidak Baik $6 \%$ dan kategori Sangat Tidak Baik 14\%. Dengan demikian dapat disimpulkan susunan 
Jurnal Bosaparis: Pendidikan Kesejahteraan Keluarga

Volume 11, Nomor 1, Maret 2020

menu di kantin karyawan Kyriad Hotel Bumiminang Padang ditinjau dari Standar Porsi dominan berada pada kategori Sangat Baik.

\section{Standar Resep}

Tabel 3. Klasifikasi Skor Variabel Susunan Menu dari Standar Resep

\begin{tabular}{lccc}
\hline \multicolumn{1}{c}{ Kategori } & Rentang Skor & Frekuensi & $\%$ \\
\hline Sangat Baik & $\geq \mathbf{3 7 , 4 5}$ & $\mathbf{2 1}$ & $\mathbf{3 2}$ \\
Baik & $35,15-37,45$ & 16 & 24 \\
Kurang Baik & $32,85-35,15$ & 18 & 27 \\
Tidak Baik & $30,55-32,85$ & 3 & 5 \\
Sangat Tidak Baik & $\leq 30,55$ & 8 & 12 \\
\hline \multicolumn{2}{r}{} & \multicolumn{3}{c}{ Sumber: Olahan Data Primer (2020) }
\end{tabular}

Berdasarkan Tabel 3 diatas terlihat bahwa responden menyatakan mengenai susunan menu kantin karyawan Kyriad Hotel Bumiminang Padang ditinjau dari Standar Resep dengan kategori Sangat Baik 32\%, kategori Baik 24\%, kategori Kurang Baik 27\%, kategori Tidak Baik 5\% dan kategori Sangat Tidak Baik 12\%. Dengan demikian dapat disimpulkan susunan menu di kantin karyawan Kyriad Hotel Bumiminang Padang ditinjau dari Standar Resep dominan berada pada kategori Sangat Baik.

\section{Standar Bumbu}

Tabel 4. Klasifikasi Skor Variabel Susunan Menu dari Standar Bumbu

\begin{tabular}{lccc}
\hline \multicolumn{1}{c}{ Kategori } & Rentang Skor & Frekuensi & $\%$ \\
\hline Sangat Baik & $\geq 34,9$ & 14 & 21 \\
Baik & $32,3-34,9$ & 17 & 26 \\
Kurang Baik & $\mathbf{2 9 , 7 - 3 2 , 3}$ & $\mathbf{2 5}$ & $\mathbf{3 8}$ \\
Tidak Baik & $27,1-29,7$ & 5 & 8 \\
Sangat Tidak Baik & $\leq 27,1$ & 5 & 7 \\
\hline \multicolumn{2}{r}{} & & \multicolumn{3}{c}{ Sumber: Olahan Data Primer (2020) }
\end{tabular}

Berdasarkan Tabel 4 diatas terlihat bahwa responden menyatakan mengenai susunan menu kantin karyawan Kyriad Hotel Bumiminang Padang ditinjau dari Standar Bumbu dengan kategori Sangat Baik 21\%, kategori Baik 26\%, kategori Kurang Baik 38\%, kategori Tidak Baik $8 \%$ dan kategori Sangat Tidak Baik 7\%. Dengan demikian dapat disimpulkan susunan menu di kantin karyawan Kyriada Hotel Bumiminang Padang ditinjau dari Standar Bumbu dominan berada pada kategori Kurang Baik.

Berdasarkan hasil penelitian yang telah dilakukan, maka dapat disimpulkan bahwa analisis susunan menu di kantin karyawan Kyriad Hotel Bumiminang Padang yang dilakukan kepada 66 responden menunjukkan bahwa variabel susunan menu dikategorikan pada kategori Baik dengan persentase 27\% pada rentang skor 100,25 - 106,45. Susunan menu terdiri dari beberapa indikator yaitu: (1) Standar Porsi yang masuk dalam kategori Sangat Baik dengan persentase $35 \%$ pada rentang skor $\geq 33,45$. (2) StandaraResep yang masuk dalam kategori Sangat Baik dengan persentase $32 \%$ dengan rentang skor $\geq 37,45$. (3) Standar Bumbu yang masuk dalam kategori Kurang Baik dengan persentase $38 \%$ dengan resntang skor 29,7 - 32,3. 
Jurnal Bosaparis: Pendidikan Kesejahteraan Keluarga

Volume 11, Nomor 1, Maret 2020

\section{Simpulan dan Saran}

Berdasarkan hasil penelitian dan pembahasan yang telah dilakukan pada bagian sebelumnya maka dapat disimpulkan hasil penelitian tentang "Analisis Susunan Menu Kantin Karyawan di Kyriad Hotel Bumiminang Padang" secara keseluruhan termasuk dalam kategori baik dengan nilai rata-rata 99,94 berada pada rentang skor 100,25 - 106,45, frekuensi 27 orangadengan persentase $41 \%$. Sedangkan berdasarkan indikator yang dapatadilihat sebagai berikut: 1) Standar Porsi berada pada kategori sangatabaik dengan nilai rata-rata 31,74 berada pada rentang skor $\geq 33,45$, frekuensi 23 orangadengan persentase $35 \%$. Jadi, dapat disimpulkan bahwa Standar Porsi berada pada kategori Sangat Baik; 2) Standar Resep berada pada kategori sangat baik dengan nilai rata-rata 35,77 berada pada rentang skor $\geq 37,45$, frekuensi 21 orang dengan persentase 32\%. Jadi, dapat disimpulkan bahwa Standar Resep berada pada kategori Sangat Baik; 3) Standar Bumbu berada pada kategori kurang baik dengan nilai rata-rata 32,42 berada pada rentang skor $29,7-32,3$, frekuensi 25 orang dengan persentase $38 \%$. Jadi, dapat disimpulkan bahwa Standar Bumbu berada pada kategori Kurang Baik.

\section{Daftar Pustaka}

Hamidah, Siti dan Komariah, Kokom. 2018. Resep dan Menu. Yogyakarta: CV Budi Utama

Sugiyono.2018.Metode Penelitian Kuantitatif.Bandung:Alfabeta. 